\title{
STRATEGI PENGEMBANGAN AGRIBISNIS TANAMAN JAGUNG PADA DINAS PERTANIAN KABUPATEN HALMAHERA UTARA
}

\author{
Munawir Muhammad \\ Staf Pengajar FAPERTA UMMU-Ternate, e-mail: -
}

\begin{abstract}
ABSTRAK
Dinas Pertanian Kabupaten Halmahera Utara merupakan Daerah dataran rendah dengan tipe lahan kering beriklim kering. Komoditas yang dominan diusahakan di Kabupaten Halmahera Utara adalah tanaman pangan (jagung) Tujuan pengkajian adalah untuk mengetahui strategi pengembangan agribisnis tanaman jagung. Pengkajian dilakukan pada Dinas Pertanian Kabupaten Halmahera Utara. Metode yang digunakan adalah surfei dan observasi lapangan, analisis data dilakukan secara deskriptif. Berdasarkan analisis SWOT, bahwa posisinya berada pada kuadran I (satu) dengan demikian jagung pada situasi yang menguntungkan yaitu sebesar 0,57. Memiliki peluang dan kekuatan sehingga harus dapat memanfaatkan peluang yang ada. Dalam kondisi ini strategi yang harus diterapkan dalam pengembangan agribisnis tanaman jagung adalah mendukung kebijakan pertumbuhan yang agresif dengan memanfaatkan kekuatan untuk meraih peluang. Strategi pengembangan agribisnis tanaman jagung dapat dilakukan dengan peningkatan sumberdaya manusia, pengembangan kelembagaan, optimisasi potensi sumberdaya alam, perbaikan pemasaran kelembagaan permodalan dan perbaikan teknologi produksi pertanian.
\end{abstract}

Kata Kunci: Strategi Pengembangan Agribisnis Tanaman Jagung

\section{PENDAHULUAN}

\subsection{Latar Belakang}

Tanaman jagung (Zea mays linn) merupakan komoditas palawija yang layak dijadikan salah satu komoditas unggulan agribisnis. Prospek pengembangan usaha tani jagung sangat cerah dalam rangka meningkatkan pendapatan dan kesejahteraan petani, sebagai sumber pendapatan negara, perluasan kesempatan kerja dan usaha peningkatan ketahanan pangan, pelestarian lingkungan penghematan devisa negara untuk menekan import dan penganekaragaman pangan (difersivikasi).

Jagung memiliki peran yang cukup penting dan strategis dalam pembangunan nasional dan regional, serta terhadap ketahanan pangan dan perbaikan perekonomian. Disamping itu jagung menjadi penarik bagi pertumbuhan industri hulu dan pendorong industri hilir di dalam sistem dan usaha agribisnis. Pengembangan tanaman jagung kedepan, dihadapkan pada era globalisasi dan tuntutan tarhadap efisiensi agar dapat bersaing di pasar global. Hal tersebut bagi departemen pertanian merupakan tantangan dan sekaligus peluang dalam merebut pasar domestik dan global, mengingat adanya keunggulan komparatif yang dimiliki seperti biaya tenaga kerja yang rendah, sumber daya alam yang melimpah (air dan tanah) dan jumlah penduduk yang besar, serta memiliki keunggulan kompetitif karena pasar produksi pertanian masih sangat dibutuhkan dengan biaya produksi yang relatif rendah.

Untuk menangkap peluang-peluang tersebut maka pengembangan agribisnis jagung perlu dilakukan dengan melibatkan stakeholder dan instansi terkait. Oleh karena itu, peran kelembagaan pertanian sangat menentukan termasuk di dalamnya lembaga koperasi serta organisasi asosiasi atau profesi. Disamping itu, perlu adanya reposisi kelembagaan koperasi yang ada di pedesaan 
saat ini agar sejalan dengan strategi pengembangan pertanian tersebut yang di cirikan dengan berdaya saing, berkerakyatan dan tersentralisasi.

Dalam pengembangan sektor agribisnis agar dapat menyesuaikan diri terhadap perubahan pasar, diperlukan pengembangan sumberdaya agribisnis, khususnya pemanfaatan dan pengembangan teknologi serta pembangunan kemampuan Sumber Daya Manusia (SDM) Agribisnis sebagai faktor pengembangan agribisnis. Dalam pengembangan teknologi, yang perlu dikembangkan adalah pengembangan teknologi aspek: Bioteknologi, teknologi ekofarming, teknologi proses, teknologi produk dan teknologi Informasi.

Demikian halnya dengan Kabupaten Halmahera Utara yang merupakan sentra pertanian jagung. Selain itu, terdapat 2 buah industri pakan ternak yaitu PT.Comexido dan PT. Hibua lamo dan beberapa industri olahan lainnya. Dengan demikian potensi Halmahera Utara untuk produksi jagung pipil kering cukup besar sebagai pemasok industri pakan ternak dan industri olahan. Hal ini sejalan dengan perkembangan usaha peternakan yang semakin bertambah.

Hasil pengkajian jagung pada Dinas Pertanian Kabupaten Halmahera Utara pada musim kemarau dengan varitas hibrida bisi-2 dapat mencapai 4 ton/ha jagung pipilan kering dengan harga jagung pipilan yaitu Rp.1.500/kg. Pemasaran jagung pipilan tersebut dilakukan oleh kelompok tani sehingga mempunyai harga tawar yang baik. Dengan demikian agribisnis jagung di wilayah sentra jagung cukup berpotensi dan mempunyai prospek yang lebih baik bila dibenahi alur tataniaganya. Untuk mengatasi pemasaran dan harga jagung yang berfluktuasi perlu dilakukan pembaharuan secara terus menerus dengan melakukan inovasi teknologi mulai dari proses produksi, pengolahan maupun pemasaran.

\subsection{Perumusan Masalah}

Berdasarkan latar belakang di atas, maka rumusan masalah yang dikemukakan dalam penelitian ini adalah" Bagaimana strategi yang dipakai dalam pengembangan agribisnis tanaman jagung pada Dinas Pertanian Kabupaten Halmahera Utara".

\subsection{Tujuan Penelitian}

Tujuan penelitian dan penulisan laporan ini yaitu untuk mengetahui strategi yang dipakai dalam pengembangan agribisnis tanaman jagung pada Dinas Pertanian Kabupaten Halmahera Utara.

\section{METODE PENELITTIAN}

\subsection{Subjek dan Objek Penelitian}

Penelitian ini dilaksanakan pada Dinas Pertanian Kabupaten Halmahera Utara. Peneliti memilih tempat ini karena dilihat dari produksi tanaman jagung sangat berkembang, baik dari kualitas tanaman jagung maupun kuantitas tanaman jagung. Data yang digunakan dalam penelitian ini adalah data primer yaitu diperoleh langsung usahatani jagung, dengan melakukan observasi dan wawancara menggunakan quesioner juga pihak lain yang berhubungan langsung dengan penelitian ini. Data sekunder diperoleh dari dinas terkait yang berhubungan dengan penelitian ini.

\subsection{Metode Analisa Data}

Analisis SWOT digunakan untuk menelaah strategi pengembangan agribisnis tanaman jagung pada Kabupaten Halmahera Utara. Analisis SWOT merupakan analisis kualitatif untuk menganalisis berbagai faktor secara sistematis untuk memformulasikan strategi suatu kegiatan. SWOT adalah singkatan dari Strengths (kekuatan), Opportunities (peluang), Weaknesses (kelemahan), dan Threat (ancaman). Dengan mengunakan matriks dapat memberikan kesimpulan tentang strategi pengembangan agribisnis tanaman jagung di Kabupaten Halmahera Utara.

Analisis ini didasarkan pada logika yang dapat memaksimalkan kekuatan (Strengths) dan peluang (Opportunities) suatu program pengelolaan. Dan secara bersamaan dapat pula meminimalkan kelemahan (Weanesses) dan ancaman (Threat).

Adapun langkah-langkah yang dilakukan dalam analisis SWOT adalah :

1. Identifikasi Kekuatan/kelemahan dan Peluang/Ancaman. 
Pada tahap ini dilakukan penelaahan kondisi faktual lapangan dan kecenderungan yang mungkin terjadi dalam mengembangkan agribisnis tanaman jagung. Hasil penelahaan ini digunakan untuk mengidentifikasi kekuatan, kelemahan, peluang dan ancaman dalam strategi pengembangan agribisnis tanaman jagung di Kabupaten Halmahera Utara.

\section{Analisis SWOT.}

Dalam menentukan strategi yang terbaik, dilakukan pemberian bobot (nilai) terhadap setiap unsur SWOT berdasarkan tingkat kepentingan dan kondisi wilayah (Tabel 1). Bobot/nilai yang diberikan berkisar antara 1- 4 . Nilai 1 tidak penting, 2 kurang penting, 3 penting dan 4 sangat penting.

Setelah masing-masing unsur SWOT diberi bobot atau nilai, unsur-unsur tersebut dihubungkan keterkaitannya untuk memperoleh beberapa alternatif kebijakan (SO, ST, WO, WT). Kemudian bobot setiap alternatif kebijakan tersebut dijumlahkan untuk menghasilkan rangking dari setiap kebijakan alternatif kebijakan yang dipriorititaskan untuk dilakukan.

3. Alternatif Kebijakan Hasil Analisis SWOT

Matriks SWOT digunakan untuk menyusun strategi pengembangan agribisnis tanaman jagung di Kabupaten Halmahera Utara. Matriks ini menggambarkan secara jelas bagaimana peluang dan ancaman yang dihadapi dalam pelaksanaan dari program. Matriks ini menghasilkan empat kemungkinan alternatif strategi, yaitu strategi $\mathrm{SO}$, strategi WO, strategi ST dan strategi WT. Tabel SWOT dapat dilihat pada Tabel 2.

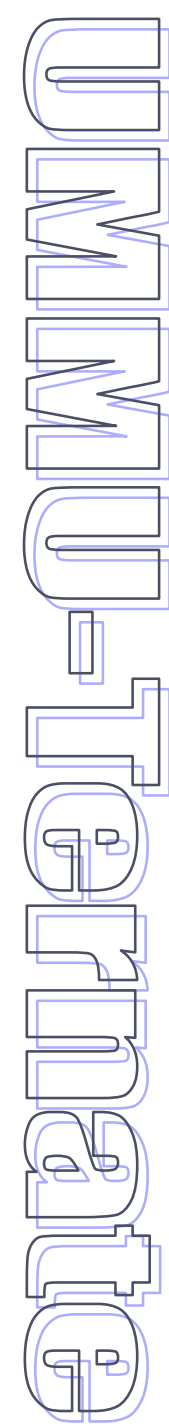

Tabel 1. Pembobotan Tiap Unsur SWOT

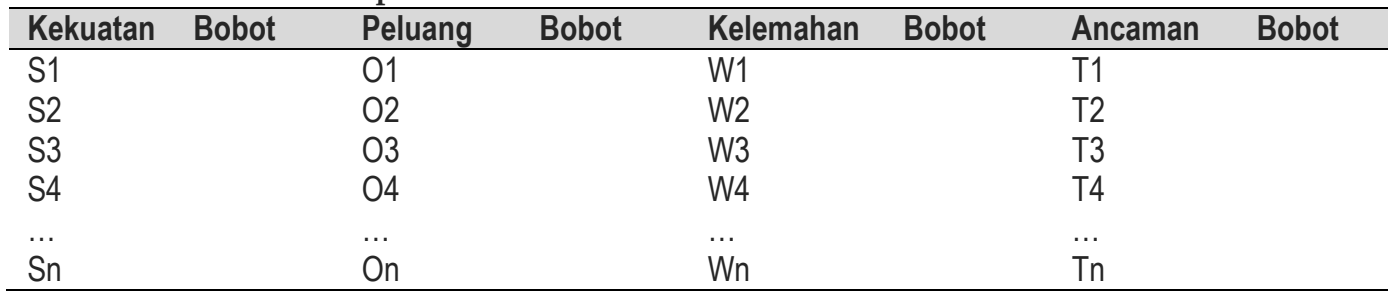

Keterangan: Nilai $4=$ sangat penting

Nilai 3 = penting

Nilai 2 = kurang penting

Nilai 1 = tidak penting

Tabel 2. Matriks SWOT

\begin{tabular}{|c|c|c|}
\hline Faktor Ekstern & $\begin{array}{l}\text { STRENGTH-S } \\
\text { Daftar faktor-faktor kekuatan }\end{array}$ & $\begin{array}{l}\text { WEANESS-W } \\
\text { Daftar faktor-faktor kelemahan }\end{array}$ \\
\hline OPPORTUNITIES-O & STRATEGI S-O & STRATEGI W-O \\
\hline Daftar faktor-faktor kekuatan & $\begin{array}{l}\text { Gunakan kekuatan untuk } \\
\text { memanfaatkan peluang }\end{array}$ & $\begin{array}{l}\text { Atasi kelemahan dengan } \\
\text { memanfaatkan peluang }\end{array}$ \\
\hline TREATS-T & STRATEGI S-T & STRATEGI W-T \\
\hline Daftar faktor-faktor kekuatan & $\begin{array}{l}\text { Gunakan kekuatan untuk } \\
\text { menghindari ancaman }\end{array}$ & $\begin{array}{l}\text { Meminimalkan kelemahan dan } \\
\text { menghindari ancaman }\end{array}$ \\
\hline
\end{tabular}

\section{HASIL DAN PEMBAHASAN}

3.1. Karakteristik Budidaya Tanaman Jagung Pada Dinas Pertanian Kabupaten Halmahera Utara

Pengelohan lahan jagung pada Dinas Pertanian yaitu melalui tahap persiapan, pembersihan, pengolahan, pemilihan bibit, dan penanaman. Pengolahan tanah bertujuan untuk memperbaiki kondisi tanah dan merangsang pertumbuhan akar. Melalui pengolahan tanah, drainase yang kurang baik akan diperbaiki. Tanah diolah pada kondisi lembab, tetapi tidak terlalu basah. Pengolahan lahan jagung meliputi pembersihan lahan dan pengolahan lahan.

\subsubsection{Persiapan Lahan}

Pembersihan lahan merupakan tahap yang penting dalam agribisnis jagung. Lahan yang akan dipakai tempat penanaman harus dibersihkan dari segala macam gulma dan akar 


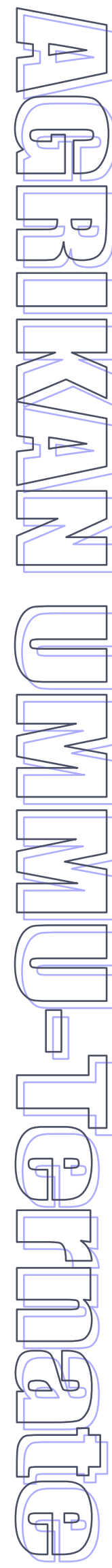

bekas tanaman. Pembersihan lahan dilakukan agar pertumbuhan akar tanaman jagung yang ditanamkan tidak terganggu dan untuk menghilangkan tumbuhan lain yang menjadi inang hama dan penyakit. Bila perlu sisa tanaman yang cukup banyak dibakar. Abunya digunakan sebagai pupuk pada tanah.

\subsubsection{Pemilihan dan Pembibitan Tanaman} Jagung

Salah satu keberhasilan agribisnis jagung tidak lepas dari ketepatan petani dalam dalam pemilihan benih yang normal, baik, dan unggul. Benih yang unggul merupakan benih yang memiliki sifat produksi tinggi, tahan penyakit, cepat bertumbuhnya, sesuai dengan tempat penanaman. Pemilihan benih yang baik erat kaitannya dengan pemilihan varietas tanaman jagung akan ditanam, hingga wajar bila pemilihan benih tanaman jagung yang baik akan menunjang keberhasilan panen jagung dimasa mendatang. Untuk itu, pemilihan benih jagung harus dilakukan secara bijak dan tepat agar produksi jagung yang dihasilkan sesuai dengan yang diinginkan.

Bibit jagung dapat langsung diperoleh dari sarana pertanian, atau dibuat sendiri. Untuk benih dari hasil penanaman sendiri, pemilihan dari beberapa tanaman jagung yang sehat pertumbuhannya, cepat bertumbuhnya, dan berasal dari jenis yang unggul. Dari tanaman terpilih, diambil jagung yang tongkolnya besar, barisan biji lurus, penuh tertutup rapat serta tidak terserang oleh hama dan penyakit.

\subsubsection{Penanaman Jagung}

Waktu menanam jagung yang baik adalah pada musim labuhan atau permulaan musim hujan, yaitu pada bulan September atau Nopember atau pada musim marengan atau saat musim hujan hampir berakhir yaitu pada bulan Februari sampai April. Pada waktu hujan, jagung siap ditanamakan. Cara penanaman yang dilakukan oleh Dinas Pertanian Kabupaten Halmahera Utara yaitu sistim legowo (agak rapat). Sistim ini banyak dipakai oleh petani jagung di dataran rendah karena sangat cocok.

Penanaman yang dilakukan oleh Dinas Pertanian Kabupaten Halmahera Utara yaitu dengan menggunakan alat penanaman (Plinter). Jarak tanama yang digunakan yaitu sistim legowo adalah panjang $20 \mathrm{~cm}$ dan lebar $80 \mathrm{~cm}$ (jagung hibrida). Sedangkan jarak tanam untuk jagung manis yaitu $20 \mathrm{~cm}$ x $40 \mathrm{~cm}$. Pada setiap titik dibuat lubang tanaman dengan ukuran lubang tanam, yang penting lubang tanam dapat memuat benih jagung. Lubang tanam dibuat dengan mesin penanaman dan setiap lubang penanaman diisi dua benih. Kedalaman lubang perlu diperhatikan supaya benih tidak terlambat pertumbuhannya. Kedalaman lubang tanaman berkisar 2-5 cm. Penanaman dengan menggunakan mesin Plinter dibutuhkan 3 orang, yaitu 1 orang sebagai pengemudi dan 2 orang sebagai pengontrol pada saat benih dan pupuk dasar yang belum tertutup rapi.

\subsubsection{Panen dan Pascapanen Jagung \\ 1. Panen}

Jagung yang siap dipanen adalah pada umur panen antara 65-70 hari (panen muda), sedangkan panen kering yaitu 103-105 hari. (Anonim, 2010). Jagung siap dipanen jika terlihat tongkol mulai mengering. Waktu panen jagung sebaiknya dilakukan pada pagi hari, karena bobot buah pada saat pagi hari dalam keadaan optimal. Panen jagung pada waktu yang kurang tepat, atau kurang masak dapat menyebabkan penurunan kualitas, butir jagung menjadi keriput. Jika telah kering, jagung akan pecah, terutama bila pipil dengan alat pipil jagung.

Winarno (1985), mengemukakan bahwa hal-hal yang perlu diperhatikan dalam kegiatan yaitu waktu panen yang berkaitan dengan umur tanaman, cara panen serta alat yang digunakan dalam pemanenan.

\section{Penanganan Pascapanen}

Beberapa hal yang perlu diperhatikan dalam penanganan pascapanen adalah alat-alat yang digunakan dalam pascapanen harus bersih. Penanganan harus cepat, cermat dan hati-hati. Hindarkan penumpukan yang berlebihan, masukan hasil jagung kedalam keranjang atau karung, sehingga jagung tidak mengalami penurunan kualitas. Jagung yang telah dipanen harus dipisahkan dari jagung yang rusak dan jagung yang sehat, kemudian dikumpulkan di tempat yang sejuk dan teduh, sehingga jagung tetap dalam keadaan segar. Selain itu jagung siap di produksi. Kegiatan pasca panen perlu dilakukan secara benar dan 


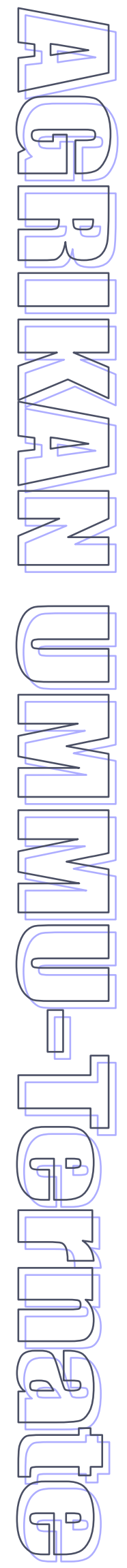

hati-hati. Sebab jagung yang telah rusak atau jelek memiliki nilai ekonomis yang rendah. Hal ini tentu sangat merugikan. (Soetrisno dkk 2003).

3.2. Hasil Analisis SWOT pada Dinas Pertanian Kabupaten Halmahera Utara

Strategi pengembangan menekan pada pengamatan dan evaluasi peluang dan ancaman lingkungan dengan melihat kekuatan dan kelemahan, oleh karena itu harus menggunakan riset pengembangan dan serta sistim informasi pengembangan dengan memperhatikan lingkungan yang terus berubah. Analisis faktor-faktor internal dan eksternal pada Dinas Pertanian Kabupaten Halmahera Utara, sangat penting dilakukan untuk menyusun strategi pengembangannya.

\subsubsection{Analisis Lingkungan Internal}

\section{Analisis Kekuatan}

Analisis lingkungan internal untuk identifikasikan faktor kekuatan yang ada pada Dinas Pertanian Kabupaten Halmahera Utara.

Sumber analisis Data Primer setelah diolah

Sumber Analisis Data Primer setelah diolah

1. Analisis peluang
Hasil analisis terhadap faktor kekuatan disajikan pada Tabel 4. Total skor untuk faktor kekuatan adalah 17,50 dan nilai tertimbang 3,38. Hasil analisis terhadap faktor kekuatan menunjukan bahwa faktor penyediaan alsintan dan pendapatan usaha tanaman jagung mempunyai skor tertinggi yaitu 4,00. Skor terendah 3,00 terdapat pada modal pengembangan dan harga produksi jagung.

2. Analisis kelemahan

Analisis lingkungan internal untuk identifikasi faktor kelemahan yang ada pada Dinas Pertanian Kabupaten Halmahera Utara. Hasil analisis faktor kelemahan untuk strategi pengembangan agribisnis tanaman jagung pada Dinas Pertanian Kabupaten Halmahera Utara di sajikan pada Tabel 5.

Hasil analisis menunjukan bahwa faktor kelemahan dengan skor tertinggi adalah pada item ketersediaan bibit dan ketersediaan pupuk $(3,50)$. Total skor untuk faktor kelemahan adalah 16,50 dan nilai tertimbang 2,81 .

Tabel 4. Hasil analisis SWOT, Kekuatan pada Dinas Pertanian Kabupaten Halmahera Utara

\begin{tabular}{|c|c|c|c|c|c|}
\hline \multirow{2}{*}{ No } & \multirow{2}{*}{ Faktor kekuatan } & \multicolumn{3}{|c|}{ Bobot } & \multirow{2}{*}{$\begin{array}{l}\text { Nilai tertimbang } \\
\text { (bobot x Rating) }\end{array}$} \\
\hline & & Skor & Nilai & Rating & \\
\hline 1 & Potensi usaha tanaman jagung & 3,50 & 0,20 & 4,00 & 0,80 \\
\hline 2 & Penyediaan alat \& mesin pertanian & 4,00 & 0,22 & 3,00 & 0,66 \\
\hline 3 & Pendapatan usaha tanaman jagung & 4,00 & 0,22 & 3,00 & 0,66 \\
\hline 4 & Modal pengembangan & 3,00 & 0,18 & 3,00 & 0,54 \\
\hline 5 & Harga produksi jagung & 3,00 & 0,18 & 4,00 & 0,72 \\
\hline & jumlah & 17,50 & 1,00 & 17,00 & 3,38 \\
\hline
\end{tabular}

Tabel 5.Hasil analisis SWOT, Kelemahan pada Dinas Pertanian Kabupaten Halmahera Utara

\begin{tabular}{|c|c|c|c|c|c|}
\hline \multirow{2}{*}{ No } & \multirow{2}{*}{ Faktor kelemahan } & \multicolumn{3}{|c|}{ Bobot } & \multirow{2}{*}{$\begin{array}{l}\text { Nilai tertimbang } \\
\text { (bobot } x \text { Rating) }\end{array}$} \\
\hline & & Skor & Nilai & Rating & \\
\hline 1 & $\begin{array}{l}\text { Pengembangan industri pengolahan } \\
\text { jagung }\end{array}$ & 3,00 & 0,19 & 2,00 & 0,38 \\
\hline 2 & Ketersediaan bibit & 3,50 & 0,20 & 3,00 & 0,60 \\
\hline 3 & Sarana dan prasarana & 3,25 & 0,20 & 3,00 & 0,60 \\
\hline 4 & Ketersediaan pupuk & 3,50 & 0,21 & 3,00 & 0,63 \\
\hline 5 & Luas lahan & 3,25 & 0,20 & 3,00 & 0,60 \\
\hline & Jumlah & 16,50 & 1,00 & 15,00 & 2,81 \\
\hline
\end{tabular}

\subsubsection{Analisis lingkungan eksternal}

Analisis lingkungan eksternal untuk identifikasi peluang pada Dianas Pertanian Kabupaten Halmahera Utara dalam pengembangan agribisnis tanaman jagung. Hasil analisis terhadap lingkungan eksternal khususnya pada faktor peluang untuk strategi pengembangan agribisnis tanaman jagung pada Dinas Pertanian Kabupaten Halmahera Utara menunjukan bahwa skor adalah pada item pola kemitraan dan diversifikasi produk olahan masih tinggi sebesar 3,50 dan yang terendah adalah item otonomi daerah, perkembangan 


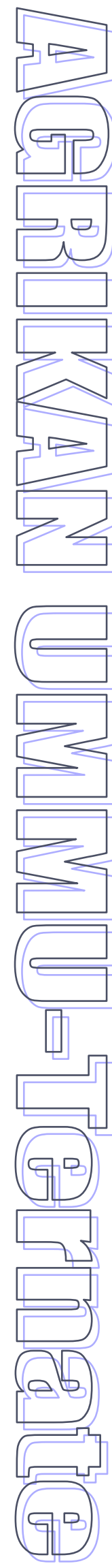

informasi dan transportasi dan penyerapan tenaga kerja yaitu 3,00. Total nilai skor untuk faktor peluang adalah 16,00 dan nilai tertimbang 3,44. Hasil analisis SWOT terhadap faktor peluang disajikan pada Tabel 6 .

\section{Analisis Ancaman}

Analisis lingkungan eksternal untuk identifikasi faktor ancaman yang ada pada Dinas Pertanian Kabupaten Halmahera Utara. Hasil analisis terhadap lingkungan eksternal khususnya pada faktor ancaman untuk strategi

Sumber Analisis Data Primer setelah diolah.

Sumber Analisis Data Primer setelah diolah

\subsubsection{Penentuan Posisi Jagung}

Hasil analisis faktor lingkungan internal dan eksternal berupa total skor perlu dilakuakan dalam mengevaluasi strategi yang dilaksanakan. Hasil analisis kekuatan dan kelemahan yang dihasilkan dari mengurangkan jumlah bobot pada peluang dengan jumlah bobot pada ancaman. Dari hasil skorsing pada Tabel 8 dapat diketahui bahwa posisi jagung dalam diagram SWOT adalah pada kondisi internal; kekuatan lebih besar dari kelemahan $(0,57)$, sedangkan pada kondisi eksternal ; Peluang lebih besar dari ancaman $(0,48)$ (Gambar 1), dimana diagram analisis SWOT menunjukan posisi pengembangan agribisnis jagung berada pada kuadran 1 (satu) atau strategi yang dibuat dengan menggunakan pengembangan agribisnis tanaman jagung pada Dinas Pertanian Kabupaten Halmahera Utara pada Tabel 7.

Hasil analisis menunjukan bahwa faktor ancaman terbesar dalam pengembangan tanaman jagung pada Dinas Pertanian Kabupaten Halmahera Utara adalah permintaan akan produk dengan nilai skor 4,00 dan terendah adalah pencemaran yaitu 2,00. Total nilai skor untuk faktor ancaman adalah 14,75 dan nilai tertimbang 2,96 .

Tabe 6. Hasil analisis SWOT, Peluang pada Dinas Pertanian Kabupaten Halmahera Utara

\begin{tabular}{|c|c|c|c|c|c|}
\hline \multirow{2}{*}{ No } & \multirow{2}{*}{ Faktor Peluang } & \multicolumn{3}{|c|}{ Bobot } & \multirow{2}{*}{$\begin{array}{l}\text { Nilai tertimbang } \\
\text { (bobot x Rating) }\end{array}$} \\
\hline & & Skor & Nilai & Rating & \\
\hline 1 & Otonomi daerah & 3,00 & 0,19 & 3,00 & 0,57 \\
\hline 2 & $\begin{array}{l}\text { Perkembangan informasi dan } \\
\text { transportasi }\end{array}$ & 3,00 & 0,19 & 3,00 & 0,57 \\
\hline 3 & Pola kemitraan & 3,50 & 0,22 & 4,00 & 0,88 \\
\hline 4 & Diversifikasi produk olahan & 3,50 & 0,22 & 4,00 & 0,88 \\
\hline 5 & Penyerapan tenaga kerja & 3,00 & 0,18 & 3,00 & 0,54 \\
\hline & Jumlah & 16,00 & 1,00 & 17,00 & 3,44 \\
\hline
\end{tabular}

Tabe 7. Hasil Analisis SWOT, Ancaman pada Dinas Pertanian Kabupaten Halmahera Utara

\begin{tabular}{clcccc}
\hline \multirow{2}{*}{ No } & \multirow{2}{*}{ Faktor Ancaman } & \multicolumn{3}{c}{ Bobot } & Nilai tertimbang \\
\cline { 3 - 4 } & & Skor & Nilai & Rating & (bobot x Rating) \\
\hline 1 & Peluang ekspor & 2,75 & 0,18 & 2,00 & 0,36 \\
2 & Perubahan ekonomi & 3,00 & 0,20 & 3,00 & 0,60 \\
3 & Pencemaran & 2,00 & 0,14 & 2,00 & 0,28 \\
4 & Permintaan akan produk & 4,00 & 0,28 & 4,00 & 1,12 \\
5 & Persaingan harga produksi & 3,00 & 0,20 & 3,00 & 0,60 \\
\hline & jumlah & $\mathbf{1 4 , 7 5}$ & $\mathbf{1 , 0 0}$ & $\mathbf{1 4 , 0 0}$ & $\mathbf{2 , 9 6}$ \\
\hline
\end{tabular}

seluruh kekuatan untuk memanfaatkan peluang yang dimiliki pengembangan agribisnis jagung yaitu strategi agresif. Untuk itu strategi yang utama yang dapat diterapkan dalam Tabel 9.

Manfaat program pengembangan Pada Dinas Pertanian Kabupaten Halmahera Utara yang akan diterima dengan adanya pengadaan traktor dan bantuan alat-alat pertanian lainnya berupa cangkul, caplak dan lainnya adalah peningkatan produktivitas jagung. Asumsi peningkatan -peningkatan penerapan teknologi pertanian didasarkan pada penerapan program intensifikasi, peningkatan sarana dan prasarana serta berbagai pelatihan, kaji terap, pendampingan hingga bantuan benih. 
Tabel 8. Hasil Skorsing Faktor Eksternal dan Internal jagung

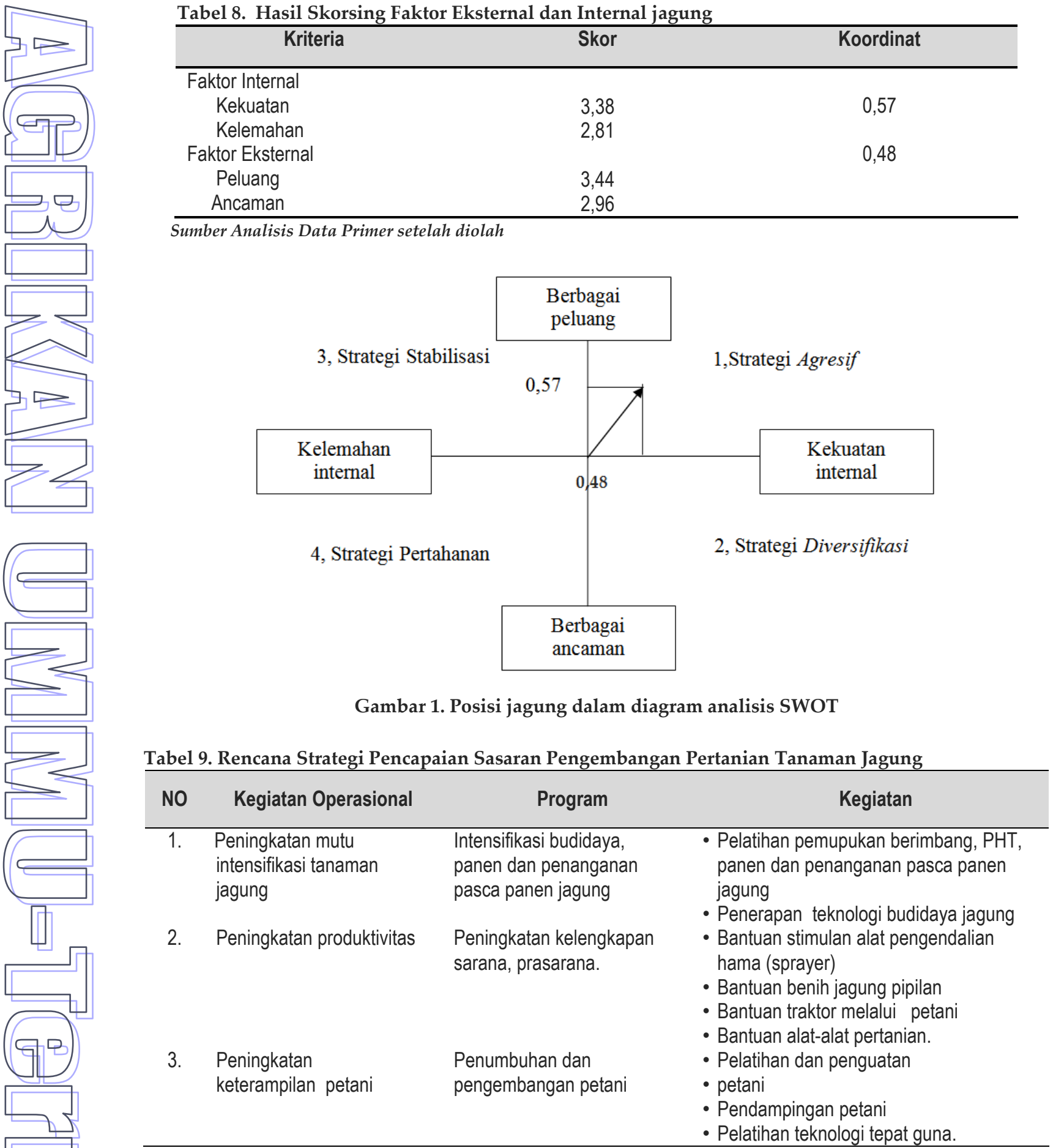

\section{P E N U T U P}

Berdasarkan kondisi dan permasalahan yang telah diuraikan, serta analisis terhadap kekuatan (potensi), kelemahan, peluang dan ancaman pada pengembangan agribisnis tanaman jagung pada dinas pertanian Kabupaten Halmahera Utara, maka dapat dikemukakan kesimpulan sebagai berikut :

1. Berdasarkan produktivitas lahan dan intensitas tanam jagung relatif masih rendah sehingga berpeluang untuk ditingkatkan. Hal ini disebabkan karena kerusakan dan penerapan teknologi budidaya masih rendah sebagai akibat rendahnya pengetahuan, keterampilan dan permodalan.

2. Dari aspek kesesuaian dan ketersediaan lahan serta analisis SWOT, pengembangan pertanian tanaman jagung pada dinas pertanian kabupaten Halmahera Utara 
layak untuk diusahakan. Hal ini juga didukung oleh ketersediaan yang menyediakan saprotan, kondisi fisik lingkungan, sosial ekonomi, serta kebutuhan pasar dan dalam kondisi ini strategi yang harus diterapkan dalam pengembangan agribisnis tanaman jagung adalah mendukung kebijakan pertumbuhan yang agresif dengan memanfaatkan kekuatan untuk meraih peluang.

3. Pelaksanaan program pengembagan produksi pertanian akan memberikan manfaat terhadap peningkatan produktivitas lahan, intensitas penanaman jagung dan peningkatan pendapatan masyarakat dari usaha yang dilakukan.

\section{DAFTAR PUSTAKA}

Agustinus, S. W. 1996. Manajemen Strategik. Binarupa Aksara. Jakarta.

Anonim, 1985. Pedoman dan Penyuluhan Pertanian. Departemen Pertanian Bogor.

Anonim, 2010. Pengembangan dan Pembinaan Kelompok Tani. Badan Industri Penyuluhan Pertanian.

Davis, J. H. and Goldberg, R. A. 1957. A Concept Of Agribusness. Harvard Business School Boston.

Departemen Pertanian, 2006. Prosidin Seminar dan Lokakarya Nasional 2005. Makassar.

Effendi, Suryatna dan Nur Sultistiati, 1991. Bercocok Tanam Jagung. CV. Yasaguna. IPB Bogor.

Firdaus, M. 2008. Manajemen Agribisnis. PT. Bumi Aksara. Jakarta.

Hadari 2003, Perencanaan Sumber Daya Manusia. Gadjah Mada University Press.

Hanafiah, K. A. 2004. Dasar-dasar Ilmu Tanah. PT. Raja Grafindo Persada. Jakarta.

Jiaravanon, S. 2007. Masa Depan Agribisnis Indonesia Prespektif Seorang Praktis. Orasi Ilmiah, Disampaikan Dalam Rangka Penerimaan Gelar Doktor Honoris Causa di Institut Pertanian Bogor. IPB Bogor.

Kotler, P. 1980. Marketing Management, New Jersey : Prentice Hall. Inc. Englewood.

Mosher, 1967. Menggerakan Dan Membangun Pertanian. CV. Jasa Guna, Jakarta

Porter, M. 1990. The Comperatif Adfantage Of Nations. The Free Press. New York.

Rukmana, H. R. dan Yudirachman H. H. 2007. Jagung, Budidaya, Pasca Panen dan Penganekaragaman Pangan. Aneka Ilmu. Jakarta.

Rangkuti, F. 2006. Analisis SWOT : Teknik Membedah Kasus Bisnis. PT. Ikrar Mandiriabadi. Jakarta. Soekartawi, 1993. Agribisnis Teori dan Aplikasi. PT. Raja Grafindo Persada. Jakarta.

Soetrisno, 2003. Pengantar Ilmu Pertanian. Penerbit Bayumedia. 